\title{
Extracellular vesicles in renal physiology and clinical applications for renal disease
}

Soon Hyo Kwon

Division of Nephrology, Hyonam Kidney Laboratory, Soonchunhyang University Seoul Hospital, Seoul, Korea

Received: April 2, 2019

Accepted: April 13, 2019

\section{Correspondence to}

\section{Soon Hyo Kwon, M.D.}

Division of Nephrology, Hyonam Kidney Laboratory, Soonchunhyang University Seoul Hospital, 59 Daesagwan-ro, Yongsan-gu,

Seoul 04401, Korea

Tel: $+82-2-710-3274$

Fax: +82-2-792-5812

E-mail: ksoonhyo@schmc.ac.kr

https://orcid.org/0000-0002-

4114-4196

This paper was contributed by The Korean Society of Nephrology.
Many cells in the nephron release extracellular vesicles (EVs). EVs envelop nucleic acids, proteins, and lipids. The surfaces of EVs express donor cell-specific markers, ligands, and major histocompatibility complex molecules. They are involved in cell-to-cell communication, immune modulation, and the removal of unwanted materials from cells. EVs have been studied as biomarkers of specific diseases and have potential therapeutic applications. Recent research has emphasized the functions of EVs in the kidney. This review provides an overview of recent findings related to the roles of EVs in the nephron, and their utility as biomarkers and therapeutic factors in renal disease.

Keywords: Extracellular vesicles; Cells; Communication; Kidney

\section{INTRODUCTION}

Extracellular vesicles (EVs) refer to all membrane-bound vesicles released from cells into the extracellular space $[1,2]$ and include exosomes, microvesicles, microparticles, ectosomes, and oncosomes [3]. The general term EVs is used in this review due to the lack of methods to specifically identify vesicles. EVs were discovered over 30 years ago [4]. Their physiological role was not well understood at first. In the last two decades, the roles of cell-derived EVs in cell-to-cell communication after intercellular contact, and in the transfer of secreted molecules, have been identified $[5,6]$. EVs are released from almost all cell types, including mammalian, prokaryotic, and plant cells. Additionally, EVs can be purified from all types of biological fluids (e.g., serum, urine, breast milk, cerebrospinal fluid, malignant ascites, bronchoalveolar lavage fluid, and saliva) [7]. EV biogenesis and release from cells is controlled by precise mechanisms $[8,9]$. In this review, the roles of EVs in the nephron, their utility as biomarkers for kidney diseases, and their therapeutic potential are discussed.

\section{Why has recent research focused on EVs?}

The number of EV studies has increased significantly, with 361, 1,228, and 4,058 published articles found in PubMed in 2000, 2010, and 2018, respectively. EVs are potential biomarkers or therapeutic tools for several diseases. They reflect the conditions of source cells, which contributes to their utility as disease biomarkers 
[10]. EVs are involved in normal physiological processes and the pathogenesis of diseases, and contain a broad and heterogeneous range of molecules [11,12]. Research indicates that cells modulate the contents of EVs in response to extracellular stress, including infection, hypoxia, oxidative stress, and other cellular stresses that alter the composition of EVs [13-16]. Changes in EV contents affect neighboring cells and alter their phenotypes, affecting disease and repair status [17-20]. The enveloped membrane protects materials from enzymatic degradation, making EVs stable carriers of enclosed materials [21]. EVs are stable over long periods of time at room temperature and after thawing from frozen [22]. The selective transfer of cell cargo is now recognized as an essential pathway for intercellular communication in both healthy and disease states. These characteristics make EVs promising disease biomarkers [23]. EVs can be detected by non-invasive liquid biopsy techniques. A biopsy is a sample of tissues or cells obtained from almost any part of the body that is used to check for markers of disease, including cancer, autoimmune diseases, and hormonal diseases. Renal disease is detected using blood or urine samples. It may eventually be possible to use small sample volumes to screen for disease and monitor disease activity in clinical settings.

Methods have been developed to modulate EV biogenesis and release, emphasizing the usefulness of EVs as a therapeutic platform [24]. Recent studies have successfully altered the contents of EVs [25]. Techniques for the precise control of EVs will facilitate their therapeutic application.

\section{THE ROLE OF EVs IN THE NEPHRON}

The role of the EV pathway in selective transfer of cell cargo is increasingly recognized as an essential process for intercellular communication [23]. Cells in the nephron constitutively release EVs under healthy conditions. EVs contain nearly identical cell surface proteins to those of their cells of origin, and can fuse to target recipient cells [7]. When EVs are taken up by recipient cells, they transfer a variety of biological molecules [26]. These materials prompt a cellular response in recipient cells. The number and content of EVs changes according to disease status [7,27-29]. A change in disease state may yield different responses in neighboring and distant cells in the body.

\section{From proximal cells to distal cells}

Studies of the biological role of EVs in intercellular communication in the nephron indicate that they may act as messengers. EVs from parent cells specifically interact with recipient cells in the nephron [30]. Recipient cells take up EVs from donor cells using cilia (Fig. 1B) [30]. Electron microscopy analyses have shown that EVs adhere to cilia and emerge from an intracellular vesicle near the base of the cilia in vivo. The uptake of EVs may be concentration-dependent [31]. Cellular stress leads to an increase in the release of EVs from cells. Podocytes are highly specialized, terminally differentiated epithelial cells, and are key sites of injury in a variety of renal diseases. Stress induces podocyte apoptosis and triggers other types of cell injury [32,33]. High glucose levels induce podocytes to generate more EVs, which are released into urine (Fig. 1A) [34]. These EVs are taken up by tubular epithelial cells and promote tubular fibrotic changes via p38 phosphorylation (Fig. 1C) [35]. This podocyte-tubular cross-talk contributes to the development of tubulointerstitial fibrosis following podocyte injury and to a decline in renal function in glomerular disease. The proximal to distal signaling pathway in the nephron has been described previously [36]. Wu et al. [36]. demonstrated that EVs from endothelial cells exposed to high glucose levels cause podocyte dysfunction. EVs shuttle from proximal to distal cells in the tubule. Proximal tubular epithelial cells affect distal tubular epithelial cells via their EVs. EV glycealdehyde-3-phosphate dehydrogenase (GAPDH) released by proximal epithelial cells regulates the epithelial sodium channel $(\mathrm{ENaC})$ in recipient distal cells and collecting duct cells (Fig. 1 G) [37]. This indicates that proximal cells contribute to the adjustment of sodium reabsorption in the distal tubule and collecting duct via EVs. Additionally, EVs transfer aquaporin-2 between cells, which may be stimulated by physiological signals (Fig. $1 \mathrm{H}$ ) [38]. Water reabsorption may also be regulated by intercellular communication via EVs. EVs from epithelial cells stimulated with a dopamine receptor agonist reduce reactive oxygen species (ROS) in distal tubule cells [31]; the mechanism underlying this decrease in ROS in recipient cells is unclear. The 


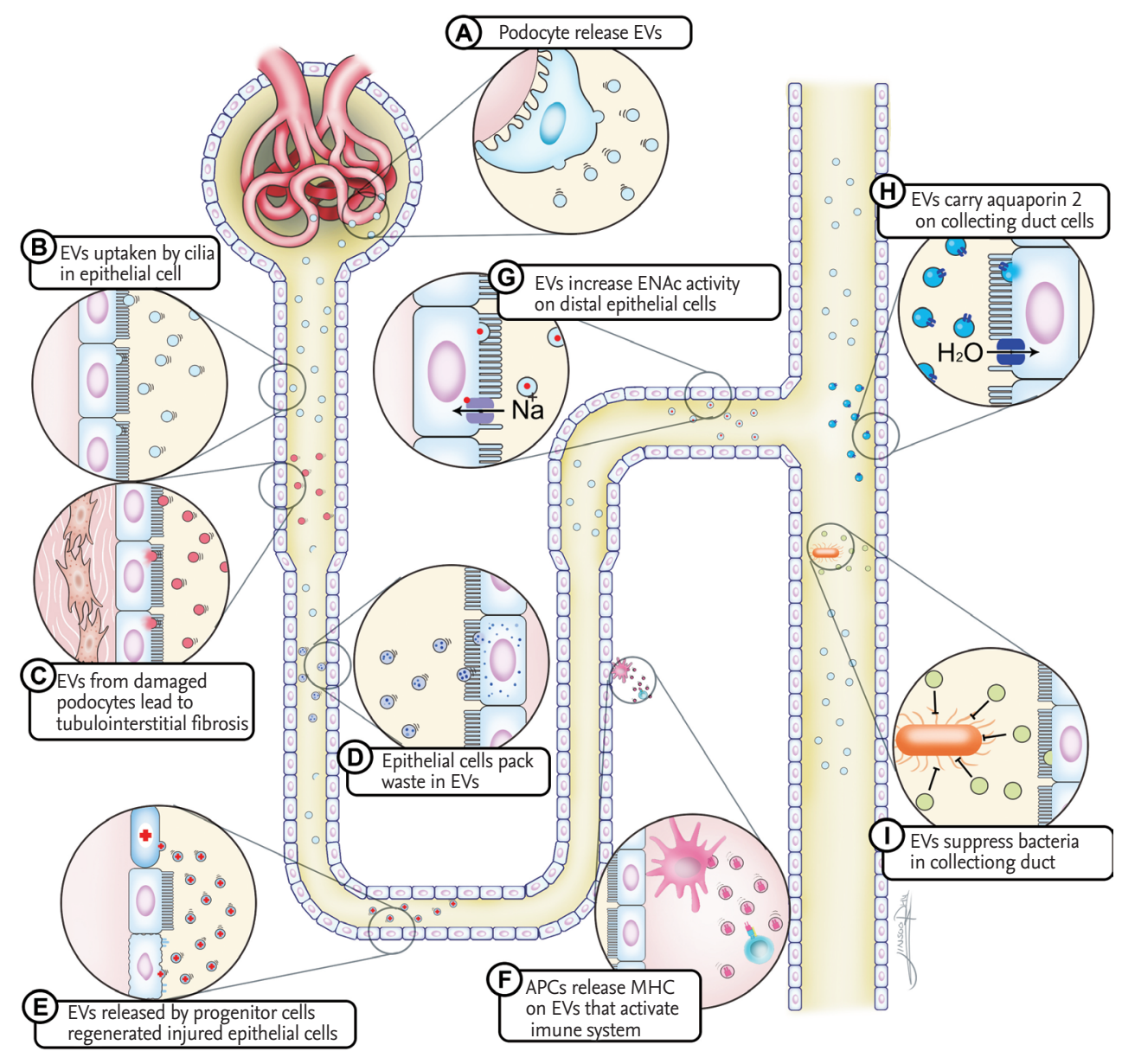

Figure 1. Extracellular vesicles (EVs) participate in cellular communication. Cells in the nephron release EVs under normal or stress conditions. EVs can amplify or limit renal damage, and may carry waste or aquaporin. APC, antigren presenting cell; MHC, major histocompatibility complex.

role and pathophysiology of nephron cell EVs require further investigation.

\section{Renal regeneration capacity of EVs}

Damage to tubular epithelial cells characterizes several kidney injuries. Tubular epithelial cell regeneration may involve paracrine, autocrine, or endocrine activity in reparative cells [39]. EVs play a role in kidney regeneration, mediating interactions between epithelial cells and stem cells via cell transition [40]. Scattered renal tubular cells undergo proliferation after injury, contributing to renal recovery (Fig. 1E) [39]. These cells confer protective effects in the ischemic kidney via the release of EVs [41]. This process can involve small RNAs and mitochondrial transfer between cells via EVs $[41,42]$.

\section{Maintenance of cellular homeostasis}

Aging induces the accumulation of damaged organelles and protein aggregation. The kidney is particularly susceptible to age-related renal damage, such as glomerulosclerosis [43]. Higher eukaryotic cells are equipped with self-defense mechanisms to maintain cellular homeostasis. One of the most important functions of EV release is the removal of waste from cells. EV secretion by reticulocytes has been identified as a mechanism underlying the eradication of molecules [44]. EVs preserve cellular homeostasis by excreting harmful materials from cells (Fig. 1D). EV secretion from cells eliminates misfolded and prion proteins [45], as well as harmful chromosomal DNA fragments [46]. The inhibition of EV secretion results in cytoplasmic accumulation of 
nuclear DNA, which induces elevated intracellular levels of ROS. EV secretion also prevents aberrant innate immune responses. Autophagy is used by all cell types to recycle nutrients, remove unwanted or damaged intracellular constituents, and as a response to starvation. The selective removal and secretion of harmful proteins, by EVs or by the autophagy-lysosomal pathway, are coordinated processes involved in protein homeostasis and the maintenance of cellular fitness [47].

\section{Immune response to urinary tract infection}

The anatomy of the urinary tract results in its continuous exposure to large numbers of bacteria. However, the urinary tract is generally sterile above the urethral meatus, indicating that an effective system maintains urine sterility by antibacterial activity. Hiemstra et al. demonstrated that EVs from the urinary tract are significantly enriched for innate immune proteins, including antimicrobial proteins and peptides, as well as bacterial and viral receptors [48]. Urinary EVs inhibit the growth of pathogenic Escherichia coli, the primary cause of urinary tract infections (UTIs) (Fig. 1I). This indicates that EVs in the urinary tract are innate immune effectors that contribute to host defense, which is consistent with other results indicating that EVs in the respiratory tract are associated with innate defense [49]. Tissue factor, the primary initiator of coagulation in vivo, is thought to play an important role in sepsis caused by UTI [50]. EV-associated tissue factor activity is related to disease severity and bacteremia in patients with febrile UTI caused by E. coli [51]. Tissue factor in EVs may prevent bacteria in the urinary tract from spreading beyond the uroepithelial barrier.

\section{EVs as carriers of native antigens}

Activated dendritic cells (DCs) release EVs with enriched major histocompatibility complex T-cell co-stimulatory molecules and adhesion molecules on their surface (Fig. 1 F) [52]. High concentrations of antigen-presenting cell-derived EVs can function as antigen-presenting vesicles for T-cell clones and primed T-cells [52,53]. EVs from activated donor DCs promote the activation of recipient DCs [54]. Additionally, EVs have been shown to induce auto-antibodies and provoke antibody-mediated rejection [55]. Suppressing the release of EVs in graft DC may prevent rejection in kidney transplantation.

\section{EVs AS KIDNEY DISEASE BIOMARKERS}

The majority of studies of exosomes in kidney disease have focused on biomarker discovery. The association of EVs with disease indicates that they may be candidate diagnostic or prognostic biomarkers.

\section{Urine contains EVs from kidney cells}

Urinary EVs are secreted by almost all kidney cell types, including glomerular epithelial cells, podocytes, proximal/distal epithelial cells, and collecting duct cells [56]. Under physiological conditions, blood EVs cannot pass through the glomerular basement membrane [57]. Because circulating (blood) EVs can be eliminated by the kidney in the acute phase, EVs may also originate from systemic circulation, although they do not account for the majority of urinary EVs [58]. Therefore, urine EVs are generally derived from kidney cells or the urinary tract. It is possible to noninvasively collect samples from patients and obtain critical information related to diagnosis, prognosis, and treatment response. Table 1 summarizes human studies of EV biomarkers in renal disease [10,27-29,59-76].

\section{Isolation and characterization of EVs}

Ultracentrifugation is a conventional technique for $\mathrm{EV}$ isolation from biological fluids. This method is not suitable for clinical research due to its low yield. Commercial kits have been developed to improve EV yield and purity. Validated plasma and serum EV isolation kits for microRNA profiling are available [77]. Improved urinary EV isolation strategies have also been developed [78]. The EV isolation kits minimize the labor, time, and clinical sample volume required. We have successfully analyzed EVs using these commercial kits $[28,29,41,79]$. Each EV isolation method has advantages and limitations; these should be considered prior to their practical application. Isolation methods for EVs have been reviewed elsewhere $[80,81]$.

\section{Sorting of EV subpopulations}

There is increasing evidence that the functional transfer of EV contents is highly selective and infrequent $[82,83]$. These findings indicate the existence of $\mathrm{EV}$ subpopulations with unique characteristics. Studies of specific EVs are required to increase our understating 
Table 1. Extracellular vesicular biomarkers in renal disease

\begin{tabular}{|c|c|c|c|}
\hline Disease & Source/method & Biomarker & Reference \\
\hline Diabetic kidney disease & $\begin{array}{l}\text { Human urine/microarray } \\
\text { Human urine/microarray } \\
\text { Human urine/proteomic analysis } \\
\text { Human urine/Western blotting }\end{array}$ & $\begin{array}{l}\text { Let-7i-3p, miR-24-3p, miR-27b-3p, miR-15b-5p } \\
\text { miR-320c, miR-6o68 } \\
\text { EV density } \\
\text { WT-1 }\end{array}$ & $\begin{array}{l}{[59]} \\
{[60]} \\
{[61]} \\
{[62]}\end{array}$ \\
\hline $\begin{array}{l}\text { IgAN and TBM } \\
\text { IgAN }\end{array}$ & Human urine/proteomic analysis & $\begin{array}{l}\text { Aminopeptidase } \mathrm{N} \text {, vasorin precursor, } \alpha-1 \\
\text { antitrypsin, ceruloplasmin } \\
\text { CCL2 mRNA }\end{array}$ & $\begin{array}{l}{[63]} \\
{[64]}\end{array}$ \\
\hline FSGS & $\begin{array}{l}\text { Human or mouse urine/immune blot } \\
\text { Human urine/qRT-PCR }\end{array}$ & $\begin{array}{l}\text { WT-1 } \\
\text { miR-193a }\end{array}$ & $\begin{array}{l}{[65]} \\
{[66]}\end{array}$ \\
\hline $\begin{array}{l}\text { Lupus nephritis } \\
\text { ADPKD }\end{array}$ & $\begin{array}{l}\text { Human urine/qRT-PCR } \\
\text { Human urine/proteomics } \\
\text { Human urine/proteomics }\end{array}$ & $\begin{array}{l}\operatorname{miR}-26 \mathrm{a} \\
\text { TMEM2 } \\
\text { Apolipoprotein A1, actin }\end{array}$ & $\begin{array}{l}{[27]} \\
{[67]} \\
{[68]}\end{array}$ \\
\hline Hypertension & $\begin{array}{l}\text { Human urine/flow cytometry } \\
\text { Human urine/qRT-PCR }\end{array}$ & $\begin{array}{l}\text { Podocyte EV number } \\
\text { miR-21, miR-92a, miR-93, miR2oob }\end{array}$ & $\begin{array}{l}{[29]} \\
{[28]}\end{array}$ \\
\hline Acute kidney injury & $\begin{array}{l}\text { Human or rat urine/Western blot } \\
\text { Human or rat urine/proteomics }\end{array}$ & $\begin{array}{l}\text { ATF3 } \\
\text { Fetuin-A }\end{array}$ & $\begin{array}{l}{[69]} \\
{[10]}\end{array}$ \\
\hline Kidney transplantation & $\begin{array}{l}\text { Human urine/Western blotting } \\
\text { Human plasma/qRT-PCR } \\
\text { Human urine/magnetic bead } \\
\text { Human urine/qRT-PCR }\end{array}$ & $\begin{array}{l}\text { NGAL } \\
\text { Gp13o, CCL4, TNF } \alpha, \mathrm{SH}_{2} \mathrm{D}_{1} \mathrm{~B} \\
\text { CD3-positive exosome } \\
\text { Bkv-miR-B1-5p, bkv-miR-B1-5p/miR-16 }\end{array}$ & $\begin{array}{l}{[70]} \\
{[71]} \\
{[72]} \\
{[73]}\end{array}$ \\
\hline Renal carcinoma & $\begin{array}{l}\text { Human plasma/qPT-PCR } \\
\text { Human urine/microarray } \\
\text { Human urine/proteomics }\end{array}$ & $\begin{array}{l}\text { lncARSR } \\
\text { GSTAı, CEBPA, PCBDı } \\
\text { MMP-9, PODXL, DKK4 }\end{array}$ & $\begin{array}{l}{[74]} \\
{[75]} \\
{[76]}\end{array}$ \\
\hline
\end{tabular}

EV, extracellular vesicle; WT-1, Wilms tumor-1; IgAN, immunoglobulin A nephropathy; TBM, thin basement membrane; qRT-PCR, quantitative real-time reverse transcriptase poly chain reaction; CCL2, chemokine ligand 2; FSGS, focal segmental glomerular sclerosis; ADPKD, autosomal dominant polycystic kidney disease; TMEM2, transmembrane protein 2; ATF3, activating transcription factor 3; NGAL, neutrophil gelatinase-associated lipocalin; Gp130, glycoprotein 130; TNF $\alpha$, tumor necrosis factor $\alpha$; $\mathrm{SH}_{2} \mathrm{D}_{1} \mathrm{~B}, \mathrm{SH} 2$ domain containing $1 \mathrm{~B}$; lncARSR, long non-coding RNA activated in RCC with sunitinib resistance; GSTA1, glutathione S-transferase alpha; CEBPA, CCAAT/enhancer-binding protein alpha; PCBD1; pterin-4 alpha-carbinolamine dehydratase; MMP-9, matrix metalloproteinase 9; PODXL, podocalyxin; DKK4, Dickkopf-related protein.

of their functions. Magneto-immunocapture methods could be utilized to obtain parent cell-specific EVs from pre-enriched EVs $[84,85]$.

\section{THERAPEUTIC APPLICATION OF EVs}

The direct delivery of therapeutic materials, such as drugs, small molecules, and nucleic acids, to target sites would effectively minimize side effects and increase efficacy. Few synthetic platforms, including polymeric nanoparticles and liposomes, have been approved by the U.S. Food and Drug Administration [86]. Recent studies have focused on enhancing biological materials, rather than developing synthetic biological carriers; EVs have gained particular attention as a therapeutic tool [25]. The EV-mediated transfer of exogenous nucleic acids was first reported in 2010 [87]. EVs have many potential therapeutic applications for renal disease, e.g., to correct metabolic deficiency, promote kidney regeneration, and modulate kidney transplant rejection. EVs can be used to carry exogenous RNA or proteins to kidney cells in vivo. It is possible to increase the efficacy of EVs by modulating their contents or their cell or organ specificity. Favorable therapeutic application characteristics include very small size, high permeability, low immunogenicity, and low risk of tumor changes. 


\section{EVs contribute to nephron repair}

EVs from stem cells, and EVs engineered with loaded materials, could contribute to nephron repair. Mesenchymal stem cells (MSCs), endothelial progenitor cells, tubular scattered cells, antigen-presenting cells, and natural killer cells secrete EVs that induce nephron regeneration or inhibit the apoptosis of tubular epithelial cells [88]. Grange et al. [89] demonstrated that labeled MSC-derived EVs target the inured kidney after intravenous injection. In human studies, MSC-derived EVs improved the glomerular filtration rate and decreased albumin excretion in patients with stage 3 or 4 chronic kidney disease [90].

The safety of MSC-based therapy requires further investigation, as MSC therapy could exacerbate preexisting kidney damage in humans [91]. The therapeutic potential of EVs is limited by their low yield from cultured cells [2]. Isolating high-purity EVs remains a challenge [92]. The dosage, routes of injection, and cellular origin of EVs affect their distribution in vivo; these factors must be standardized for clinical trials [93]. The storability of EVs is also an important consideration. It may prove difficult to maintain the therapeutic activity of stem/progenitor cell-derived EVs in vitro prior to engraftment in the renal parenchyma [88]. It is not certain that cryopreserved stem/progenitor cell-derived EVs are as effective as freshly isolated stem/progenitor cell-derived EVs [94]. Finally, it is necessary to develop a tracking tool to determine the abundance of stem/progenitor cell-derived EVs following administration.

\section{Loading of EVs with therapeutic materials}

Methods for loading EVs include drug loading, for example through chemicals, proteins, or genetic materials, in purified EVs ex vivo [4], as well as pre-loading drugs or therapeutic factors to donor cells prior to EV purification [95].

Curcumin, doxorubicin, and paclitaxel have been successfully loaded into EVs [96]. EVs exhibit a higher loading efficiency and capacity for hydrophobic chemical drugs compared to liposomes [97]. Non-coding RNAs are attractive drug targets for treating renal disease [98]. Engineered anti-RNA oligonucleotides can prevent specific mRNAs from binding to miRNAs, thus inhibiting their function. Didiot et al. [99] developed a robust and scalable method for loading therapeutic
RNA into EVs with co-incubation. Cholesterol conjugation and sonication are suitable alternatives for active loading of RNA with minimal aggregation and degradation $[100,101]$.

Therapeutic agents can be incorporated into EVs from parent cells. Chemically treated MSCs release EVs with anti-proliferative activity against cancer cells in vitro [102]. MSCs engineered to overexpress miRNA-let7c were injected into mice with unilateral ureteral obstruction, thereby attenuating kidney injury [103].

\section{CONCLUSIONS}

EVs are promising biomarkers and active physiological agents with many possible therapeutic applications. Research has improved our understanding of EV characteristics but further investigation of the roles of EVs in the kidney is required. Host cell EVs can have beneficial or harmful effects on recipient cells. Despite the positive results of several EV studies, consistency has been lacking. Further research will improve our ability to modulate signaling mechanisms in the nephron and improve treatments for kidney diseases.

\section{Conflict of interest}

No potential conflict of interest relevant to this article was reported.

\section{Acknowledgments}

This research was partially supported by the National Research Foundation of Korea (NRF) funded by the Ministry of Education (NRF-2017R1D1A3B03029800) and the Soonchunhyang University Research Fund.

\section{REFERENCES}

1. Iraci N, Leonardi T, Gessler F, Vega B, Pluchino S. Focus on extracellular vesicles: physiological role and signalling properties of extracellular membrane vesicles. Int J Mol Sci 2016;17:171.

2. Baranyai T, Herczeg K, Onodi Z, et al. Isolation of exosomes from blood plasma: qualitative and quantitative comparison of ultracentrifugation and size exclusion chromatography methods. PLoS One 2015;10:e0145686. 
3. van der Pol E, Boing AN, Gool EL, Nieuwland R. Recent developments in the nomenclature, presence, isolation, detection and clinical impact of extracellular vesicles. J Thromb Haemost 2016;14:48-56.

4. Trams EG, Lauter CJ, Salem N Jr, Heine U. Exfoliation of membrane ecto-enzymes in the form of micro-vesicles. Biochim Biophys Acta 1981;645:63-70.

5. Holme PA, Solum NO, Brosstad F, Roger M, Abdelnoor M. Demonstration of platelet-derived microvesicles in blood from patients with activated coagulation and fibrinolysis using a filtration technique and western blotting. Thromb Haemost 1994;72:666-671.

6. Hess C, Sadallah S, Hefti A, Landmann R, Schifferli JA. Ectosomes released by human neutrophils are specialized functional units. J Immunol 1999;163:4564-4573.

7. Raposo G, Stoorvogel W. Extracellular vesicles: exosomes, microvesicles, and friends. J Cell Biol 2013;200:373-383.

8. Janas T, Janas MM, Sapon K, Janas T. Mechanisms of RNA loading into exosomes. FEBS Lett 2015;589:1391-1398.

9. Park SJ, Kim JM, Kim J, et al. Molecular mechanisms of biogenesis of apoptotic exosome-like vesicles and their roles as damage-associated molecular patterns. Proc Natl Acad Sci U S A 2018;115:E11721-E11730.

10. Zhou H, Pisitkun T, Aponte A, et al. Exosomal fetuin-A identified by proteomics: a novel urinary biomarker for detecting acute kidney injury. Kidney Int 2006;70:1847-1857.

11. Kalra H, Simpson RJ, Ji H, et al. Vesiclepedia: a compendium for extracellular vesicles with continuous community annotation. PLoS Biol 2012;10:e1001450.

12. Kim DK, Lee J, Kim SR, et al. EVpedia: a community web portal for extracellular vesicles research. Bioinformatics 2015;31:933-939.

13. Lancaster GI, Febbraio MA. Exosome-dependent trafficking of HSP7o: a novel secretory pathway for cellular stress proteins. J Biol Chem 2005;280:23349-23355.

14. Eldh M, Ekstrom K, Valadi H, et al. Exosomes communicate protective messages during oxidative stress: possible role of exosomal shuttle RNA. PLoS One 2010;5:e15353.

15. Pegtel DM, Cosmopoulos K, Thorley-Lawson DA, et al. Functional delivery of viral miRNAs via exosomes. Proc Natl Acad Sci U S A 2010;107:6328-6333.

16. de Jong OG, Verhaar MC, Chen Y, et al. Cellular stress conditions are reflected in the protein and RNA content of endothelial cell-derived exosomes. J Extracell Vesicles 2012;1:18396.

17. Hristov M, Erl W, Linder S, Weber PC. Apoptotic bodies from endothelial cells enhance the number and initiate the differentiation of human endothelial progenitor cells in vitro. Blood 2004;104:2761-2766.

18. Rak J, Guha A. Extracellular vesicles: vehicles that spread cancer genes. Bioessays 2012;34:489-497.

19. Camussi G, Deregibus MC, Bruno S, Grange C, Fonsato V, Tetta C. Exosome/microvesicle-mediated epigenetic reprogramming of cells. Am J Cancer Res 2011;1:98-110.

20. Al-Nedawi K, Meehan B, Micallef J, et al. Intercellular transfer of the oncogenic receptor EGFRvIII by microvesicles derived from tumour cells. Nat Cell Biol 2008;10:619624 .

21. Boukouris S, Mathivanan S. Exosomes in bodily fluids are a highly stable resource of disease biomarkers. Proteomics Clin Appl 2015;9:358-367.

22. Jeyaram A, Jay SM. Preservation and storage stability of extracellular vesicles for therapeutic applications. AAPS J 2017;20:1.

23. Mittelbrunn M, Gutierrez-Vazquez C, Villarroya-Beltri C, et al. Unidirectional transfer of microRNA-loaded exosomes from T cells to antigen-presenting cells. Nat Commun 2011;2:282.

24. Wang X, Thompson CD, Weidenmaier C, Lee JC. Release of Staphylococcus aureus extracellular vesicles and their application as a vaccine platform. Nat Commun 2018;9:1379.

25. Mentkowski KI, Snitzer JD, Rusnak S, Lang JK. Therapeutic potential of engineered extracellular vesicles. AAPS J 2018;20:50.

26. Valadi H, Ekstrom K, Bossios A, Sjostrand M, Lee JJ, Lotvall JO. Exosome-mediated transfer of mRNAs and microRNAs is a novel mechanism of genetic exchange between cells. Nat Cell Biol 2007;9:654-659.

27. Ichii O, Otsuka-Kanazawa S, Horino T, et al. Decreased miR-26a expression correlates with the progression of podocyte injury in autoimmune glomerulonephritis. PLoS One 2014;9:e110383.

28. Kwon SH, Tang H, Saad A, et al. Differential expression of microRNAs in urinary extracellular vesicles obtained from hypertensive patients. Am J Kidney Dis 2016;68:331332.

29. Kwon SH, Woollard JR, Saad A, et al. Elevated urinary podocyte-derived extracellular microvesicles in renovascular hypertensive patients. Nephrol Dial Transplant 2017;32:800-807.

30. Hogan MC, Manganelli L, Woollard JR, et al. Character- 
ization of PKD protein-positive exosome-like vesicles. J Am Soc Nephrol 2009;20:278-288.

31. Gildea JJ, Seaton JE, Victor KG, et al. Exosomal transfer from human renal proximal tubule cells to distal tubule and collecting duct cells. Clin Biochem 2014;47:89-94.

32. Kriz W, Shirato I, Nagata M, LeHir M, Lemley KV. The podocyte's response to stress: the enigma of foot process effacement. Am J Physiol Renal Physiol 2013;304:F333-F347.

33. Min SY, Ha DS, Ha TS. Puromycin aminonucleoside triggers apoptosis in podocytes by inducing endoplasmic reticulum stress. Kidney Res Clin Pract 2018;37:210-221.

34. Burger D, Thibodeau JF, Holterman CE, Burns KD, Touyz RM, Kennedy CR. Urinary podocyte microparticles identify prealbuminuric diabetic glomerular injury. J Am Soc Nephrol 2014;25:1401-1407.

35. Munkonda MN, Akbari S, Landry C, et al. Podocyte-derived microparticles promote proximal tubule fibrotic signaling via p38 MAPK and $\mathrm{CD}_{3} 6$. J Extracell Vesicles 2018;7:1432206.

36. Wu X, Gao Y, Xu L, et al. Exosomes from high glucose-treated glomerular endothelial cells trigger the epithelial-mesenchymal transition and dysfunction of podocytes. Sci Rep 2017;7:9371.

37. Jella KK, Yu L, Yue Q, Friedman D, Duke BJ, Alli AA. Exosomal GAPDH from proximal tubule cells regulate ENaC activity. PLoS One 2016;11:e0165763.

38. Street JM, Birkhoff W, Menzies RI, Webb DJ, Bailey MA, Dear JW. Exosomal transmission of functional aquaporin 2 in kidney cortical collecting duct cells. J Physiol 2011;589:6119-6127.

39. Smeets B, Boor P, Dijkman H, et al. Proximal tubular cells contain a phenotypically distinct, scattered cell population involved in tubular regeneration. J Pathol 2013;229:645-659.

40. Chiabotto G, Bruno S, Collino F, Camussi G. Mesenchymal stromal cells epithelial transition induced by renal tubular cells-derived extracellular vesicles. PLoS One 2016;11:e0159163.

41. Zou X, Kwon SH, Jiang K, et al. Renal scattered tubular-like cells confer protective effects in the stenotic murine kidney mediated by release of extracellular vesicles. Sci Rep 2018;8:1263.

42. Guescini M, Genedani S, Stocchi V, Agnati LF. Astrocytes and glioblastoma cells release exosomes carrying $\mathrm{mtD}$ NA. J Neural Transm (Vienna) 2010;117:1-4.

43. Bolignano D, Mattace-Raso F, Sijbrands EJ, Zoccali C. The aging kidney revisited: a systematic review. Ageing Res Rev 2014;14:65-80.

44. Johnstone RM, Adam M, Hammond JR, Orr L, Turbide C. Vesicle formation during reticulocyte maturation. Association of plasma membrane activities with released vesicles (exosomes). J Biol Chem 1987;262:9412-9420.

45. Guo BB, Bellingham SA, Hill AF. The neutral sphingomyelinase pathway regulates packaging of the prion protein into exosomes. J Biol Chem 2015;290:3455-3467.

46. Takahashi A, Okada R, Nagao K, et al. Exosomes maintain cellular homeostasis by excreting harmful DNA from cells. Nat Commun 2017;8:15287.

47. Baixauli F, Lopez-Otin C, Mittelbrunn M. Exosomes and autophagy: coordinated mechanisms for the maintenance of cellular fitness. Front Immunol 2014;5:403.

48. Hiemstra TF, Charles PD, Gracia T, et al. Human urinary exosomes as innate immune effectors. J Am Soc Nephrol 2014;25:2017-2027.

49. Kesimer M, Scull M, Brighton B, et al. Characterization of exosome-like vesicles released from human tracheobronchial ciliated epithelium: a possible role in innate defense. FASEB J 2009;23:1858-1868.

50. Creasey AA, Chang AC, Feigen L, Wun TC, Taylor FB Jr, Hinshaw LB. Tissue factor pathway inhibitor reduces mortality from Escherichia coli septic shock. J Clin Invest 1993;91:2850-2860.

51. Woei-A-Jin FJ, van der Starre WE, Tesselaar ME, et al. Procoagulant tissue factor activity on microparticles is associated with disease severity and bacteremia in febrile urinary tract infections. Thromb Res 2014;133:799-803.

52. Segura E, Nicco C, Lombard B, et al. ICAM-1 on exosomes from mature dendritic cells is critical for efficient naive T-cell priming. Blood 2005;106:216-223.

53. Montecalvo A, Shufesky WJ, Stolz DB, et al. Exosomes as a short-range mechanism to spread alloantigen between dendritic cells during $\mathrm{T}$ cell allorecognition. J Immunol 2008;180:3081-3090.

54. Montecalvo A, Larregina AT, Shufesky WJ, et al. Mechanism of transfer of functional microRNAs between mouse dendritic cells via exosomes. Blood 2012;119:756-766.

55. Dieude M, Bell C, Turgeon J, et al. The $20 \mathrm{~S}$ proteasome core, active within apoptotic exosome-like vesicles, induces autoantibody production and accelerates rejection. Sci Transl Med 2015;7:318ra200.

56. Miranda KC, Bond DT, McKee M, et al. Nucleic acids within urinary exosomes/microvesicles are potential bio- 
markers for renal disease. Kidney Int 2010;78:191-199.

57. Pisitkun T, Shen RF, Knepper MA. Identification and proteomic profiling of exosomes in human urine. Proc Natl Acad Sci U S A 2004;101:13368-13373.

58. Cheng Y, Wang X, Yang J, et al. A translational study of urine miRNAs in acute myocardial infarction. J Mol Cell Cardiol 2012;53:668-676.

59. Prabu P, Rome S, Sathishkumar C, et al. MicroRNAs from urinary extracellular vesicles are non-invasive early biomarkers of diabetic nephropathy in type 2 diabetes patients with the 'Asian Indian phenotype'. Diabetes Metab 2018 Aug 27 [Epub]. https://doi.org/10.1016/j.diabet.2018.08.004.

6o. Delic D, Eisele C, Schmid R, et al. Urinary exosomal miRNA signature in type II diabetic nephropathy patients. PLoS One 2016;11:e0150154.

61. Kaminska A, Platt M, Kasprzyk J, et al. Urinary extracellular vesicles: potential biomarkers of renal function in diabetic patients. J Diabetes Res 2016;2016:5741518.

62. Kalani A, Mohan A, Godbole MM, et al. Wilm's tumor-1 protein levels in urinary exosomes from diabetic patients with or without proteinuria. PLoS One 2013;8:e60177.

63. Moon PG, Lee JE, You S, et al. Proteomic analysis of urinary exosomes from patients of early IgA nephropathy and thin basement membrane nephropathy. Proteomics 2011;11:2459-2475.

64. Feng Y, Lv LL, Wu WJ, et al. Urinary exosomes and exosomal CCL2 mRNA as biomarkers of active histologic injury in IgA nephropathy. Am J Pathol 2018;188:2542-2552.

65. Zhou H, Kajiyama H, Tsuji T, et al. Urinary exosomal Wilms' tumor-1 as a potential biomarker for podocyte injury. Am J Physiol Renal Physiol 2013;305:F553-F559.

66. Huang Z, Zhang Y, Zhou J, Zhang Y. Urinary exosomal miR-193a can be a potential biomarker for the diagnosis of primary focal segmental glomerulosclerosis in children. Biomed Res Int 2017;2017:7298160.

67. Hogan MC, Bakeberg JL, Gainullin VG, et al. Identification of biomarkers for PKD1 using urinary exosomes. J Am Soc Nephrol 2015;26:1661-1670.

68. Pocsfalvi G, Raj DA, Fiume I, Vilasi A, Trepiccione F, Capasso G. Urinary extracellular vesicles as reservoirs of altered proteins during the pathogenesis of polycystic kidney disease. Proteomics Clin Appl 2015;9:552-567.

69. Zhou H, Cheruvanky A, Hu X, et al. Urinary exosomal transcription factors, a new class of biomarkers for renal disease. Kidney Int 2008;74:613-621.

70. Alvarez S, Suazo C, Boltansky A, et al. Urinary exosomes as a source of kidney dysfunction biomarker in renal transplantation. Transplant Proc 2013;45:3719-3723.

71. Zhang H, Huang E, Kahwaji J, et al. Plasma exosomes from HLA-sensitized kidney transplant recipients contain mRNA transcripts which predict development of antibody-mediated rejection. Transplantation 2017;101:24192428.

72. Park J, Lin HY, Assaker JP, et al. Integrated kidney exosome analysis for the detection of kidney transplant rejection. ACS Nano 2017;11:11041-11046.

73. Kim MH, Lee YH, Seo JW, et al. Urinary exosomal viral microRNA as a marker of BK virus nephropathy in kidney transplant recipients. PLoS One 2017;12:e0190068.

74. Qu L, Ding J, Chen C, et al. Exosome-transmitted lncARSR promotes sunitinib resistance in renal cancer by acting as a competing endogenous RNA. Cancer Cell 2016;29:653-668.

75. De Palma G, Sallustio F, Curci C, et al. The three-gene signature in urinary extracellular vesicles from patients with clear cell renal cell carcinoma. J Cancer 2016;7:19601967.

76. Raimondo F, Morosi L, Corbetta S, et al. Differential protein profiling of renal cell carcinoma urinary exosomes. Mol Biosyst 2013;9:1220-1233.

77. Ding M, Wang C, Lu X, et al. Comparison of commercial exosome isolation kits for circulating exosomal microRNA profiling. Anal Bioanal Chem 2018;410:3805-3814.

78. Gheinani AH, Vogeli M, Baumgartner U, et al. Improved isolation strategies to increase the yield and purity of human urinary exosomes for biomarker discovery. Sci Rep 2018;8:3945.

79. Bae YU, Kim Y, Lee H, et al. Bariatric surgery alters microRNA content of circulating exosomes in patients with obesity. Obesity (Silver Spring) 2019;27:264-271.

8o. Xu R, Greening DW, Zhu HJ, Takahashi N, Simpson RJ. Extracellular vesicle isolation and characterization: toward clinical application. J Clin Invest 2016;126:1152-1162.

81. Merchant ML, Rood IM, Deegens JKJ, Klein JB. Isolation and characterization of urinary extracellular vesicles: implications for biomarker discovery. Nat Rev Nephrol 2017;13:731-749.

82. Squadrito ML, Baer C, Burdet F, et al. Endogenous RNAs modulate microRNA sorting to exosomes and transfer to acceptor cells. Cell Rep 2014;8:1432-1446.

83. Alexander M, Hu R, Runtsch MC, et al. Exosome-delivered microRNAs modulate the inflammatory response to 
endotoxin. Nat Commun 2015;6:7321.

84. Hong CS, Muller L, Boyiadzis M, Whiteside TL. Isolation and characterization of $\mathrm{CD}_{34}$ + blast-derived exosomes in acute myeloid leukemia. PLoS One 2014;9:e103310.

85. Hubal MJ, Nadler EP, Ferrante SC, et al. Circulating adipocyte-derived exosomal MicroRNAs associated with decreased insulin resistance after gastric bypass. Obesity (Silver Spring) 2017;25:102-110.

86. Bobo D, Robinson KJ, Islam J, Thurecht KJ, Corrie SR. Nanoparticle-based medicines: a review of FDA-approved materials and clinical trials to date. Pharm Res 2016;33:2373-2387.

87. Zhang Y, Liu D, Chen X, et al. Secreted monocytic miR150 enhances targeted endothelial cell migration. Mol Cell 2010;39:133-144.

88. Lv LL, Wu WJ, Feng Y, Li ZL, Tang TT, Liu BC. Therapeutic application of extracellular vesicles in kidney disease: promises and challenges. J Cell Mol Med 2018;22:728-737.

89. Grange C, Tapparo M, Bruno S, et al. Biodistribution of mesenchymal stem cell-derived extracellular vesicles in a model of acute kidney injury monitored by optical imaging. Int J Mol Med 2014;33:1055-1063.

90. Nassar W, El-Ansary M, Sabry D, et al. Umbilical cord mesenchymal stem cells derived extracellular vesicles can safely ameliorate the progression of chronic kidney diseases. Biomater Res 2016;20:21.

91. Kim JS, Lee JH, Kwon O, et al. Rapid deterioration of preexisting renal insufficiency after autologous mesenchymal stem cell therapy. Kidney Res Clin Pract 2017;36:200204.

92. Sodar BW, Kittel A, Paloczi K, et al. Low-density lipoprotein mimics blood plasma-derived exosomes and microvesicles during isolation and detection. Sci Rep 2016;6:24316.

93. Wiklander OP, Nordin JZ, O'Loughlin A, et al. Extracellular vesicle in vivo biodistribution is determined by cell source, route of administration and targeting. J Extracell Vesicles 2015;4:26316.

94. Lener T, Gimona M, Aigner L, et al. Applying extracellular vesicles based therapeutics in clinical trials: an ISEV position paper. J Extracell Vesicles 2015;4:30087.

95. Caby MP, Lankar D, Vincendeau-Scherrer C, Raposo G, Bonnerot C. Exosomal-like vesicles are present in human blood plasma. Int Immunol 2005;17:879-887.

96. Kim SM, Kim HS. Engineering of extracellular vesicles as drug delivery vehicles. Stem Cell Investig 2017;4:74.

97. Fuhrmann G, Serio A, Mazo M, Nair R, Stevens MM. Active loading into extracellular vesicles significantly improves the cellular uptake and photodynamic effect of porphyrins. J Control Release 2015;205:35-44.

98. Kato M. Noncoding RNAs as therapeutic targets in early stage diabetic kidney disease. Kidney Res Clin Pract 2018;37:197-209.

99. Didiot MC, Hall LM, Coles AH, et al. Exosome-mediated delivery of hydrophobically modified siRNA for huntingtin mRNA silencing. Mol Ther 2016;24:1836-1847.

100. Lamichhane TN, Jeyaram A, Patel DB, et al. Oncogene knockdown via active loading of small RNAs into extracellular vesicles by sonication. Cell Mol Bioeng 2016;9:315324.

101. Stremersch S, Vandenbroucke RE, Van Wonterghem E, Hendrix A, De Smedt SC, Raemdonck K. Comparing exosome-like vesicles with liposomes for the functional cellular delivery of small RNAs. J Control Release 2016;232:51-61.

102. Pascucci L, Cocce V, Bonomi A, et al. Paclitaxel is incorporated by mesenchymal stromal cells and released in exosomes that inhibit in vitro tumor growth: a new approach for drug delivery. J Control Release 2014;192:262-270.

103. Wang B, Yao K, Huuskes BM, et al. Mesenchymal stem cells deliver exogenous MicroRNA-let7c via exosomes to attenuate renal fibrosis. Mol Ther 2016;24:1290-1301. 